\title{
Querubismo, un caso clínico
}

\author{
FERNANDO SUÁREZ-OBANDO MD ${ }^{1}$. MARÍA LUCILA VIASUS MD. ${ }^{2}$
}

1. Genetista Instituto de Genética Humana. Pontificia Universidad Javeriana. Bogotá D.C. Colombia.

2. Pediatra Universidad Militar Nueva Granada. Bogotá D.C. Colombia.

\begin{abstract}
Cherubism, a case-report

Cherubism is a benign osteofibrous disorder affecting facial bones. It is produced by an abnormal functioning of osteoblasts and osteoclasts, leading to replacement of normal bone by cellular fibrous tissue and immature bone, producing painless progressive growing of the jaw, with round facial appearance. Case-report: An 11 years-old female patient is presented, with 8 years of progressive facial swelling. The clinical and radiologic diagnosis of cherubism was confirmed by molecular analysis, detecting de novo mutation in SH3BP2 gene.

(Key words: cherubism, mutation, genes, dominant).

Rev Chil Pediatr 2009; 80 (1): 65-69
\end{abstract}

\section{RESUMEN}

El Querubismo es una alteración osteofibrosa benigna que los huesos de la cara originada por un funcionamiento anormal de osteoblastos y osteoclastos que ocasiona reemplazo de tejido óseo por matriz fibrosa y hueso inmaduro que como consecuencia desarrolla un crecimiento progresivo no doloroso de la mandíbula, dando un aspecto redondeado a la cara. Caso clínico: Se prresenta un caso de Querubismo en una paciente de 11 años de edad, con cuadro de 8 años de evolución de aumento progresivo del volumen facial, el cuadro clínico y radiológico de Querubismo fue confirmado por el análisis molecular que detecto una mutación de novo en el gen SH3BP2.

(Palabras clave: Querubismo, mutación, genes dominantes).

Rev Chil Pediatr 2009; 80 (1): 65-69

\section{Introducción}

El Querubismo (OMIM 118400) es un desorden infrecuente de herencia autosómica dominante, que se manifiesta en la infancia tem- prana $^{1}$, y se caracteriza por una progresiva proliferación ósea de tipo quístico, ocasionada por el funcionamiento anormal de osteoblastos y osteoclastos durante el remodelamiento óseo; esta patología afecta la mayoría de los huesos

Trabajo recibido el 22 de septiembre de 2008, aceptado para publicación el 17 de noviembre de 2008.

Correspondencia a:

Fernando Suárez-Obando

E-mail: fernando.suarez@javeriana.edu.co 
faciales, pero compromete principalmente el maxilar inferior ${ }^{2}$, desarrollándose un desmesurado crecimiento que deteriora el balance funcional y estético de la cara ${ }^{3}$. El Querubismo está clasificado dentro del grupo de lesiones osteo-fibrosas benignas, diferenciándose de las lesiones osteo-cementarias y las displasias fibrosas ${ }^{4}$ debido a su particular presentación clínica y radiológica. El término Querubismo fue sugerido por Jones ${ }^{5}$, con el propósito de describir la apariencia de las personas afectadas que tienen semejanza a la de un querubín del arte renacentista ${ }^{6}$. Se presenta un caso de Querubismo con compromiso bilateral del piso orbitario junto con la descripción radiológica y la confirmación molecular del caso a través de la detección de una mutación puntual en el gen $\mathrm{SH} 3 \mathrm{BP} 2$ (SH3-domain binding protein 2).

\section{Caso Clínico}

Paciente de 11 años de edad, de sexo femenino, con cuadro de 8 años de evolución de aumento progresivo no doloroso de la distancia bigonial y bicigomática asociada a fascies aparentemente edematosa e incremento general del volumen facial (figura 1). A los dos años de evolución se asocia proptosis, diplopía binocular y disminución de la agudeza visual. La paciente fue producto de un tercer embarazo, parto vaginal a las 39 semanas con talla de $51 \mathrm{~cm}$ (percentil 50), peso de $3200 \mathrm{~g}$ (percentil 25-50) y perímetro cefálico de $35 \mathrm{~cm}$ (percentil 90). La primera dentición fue a los 8 meses, con la pieza dentaria 51 , el primer cambio de dentición se presento a los 7 años y aun no ha finalizado. El reemplazo de los incisivos centrales superiores e inferiores fue entre $\operatorname{los} 7$ y 9 años. Dentro de los antecedentes familiares la hermana (16 años), el padre (46 años) y el abuelo (70 años), presentan genu valgum congénito documentado clínica y radiológicamente, hermano menor de 9 años sano. El padre de la paciente ha desarrollado osteoatritis de cadera que requirió reemplazo a los 41 años de edad. La madre de la paciente padece de Artritis Reumatoidea.

Al examen físico la paciente presenta una talla de $129 \mathrm{~cm}$ (percentil 5), peso de $45 \mathrm{~kg}$ (percentil 90), perímetro cefálico de $51 \mathrm{~cm}$ (percentil 25-50), distancia intercantal interna: $3,5 \mathrm{~cm}$ (entre +1 y +2 desviaciones estándar), distancia intercantal externa de 11,5 cm (por encima de +3 desviaciones estándar). Altura facial (nasion-gnation) de $11 \mathrm{cms}(+1$ desviación estándar), ancho facial o distancia bicigomática (zigión-zigión) de $15 \mathrm{~cm}$ (por encima de +2 desviaciones estándar), índice facial: 73 (por debajo de -2 desviaciones estándar). En la cara se evidenciaba hipertelorismo, proptosis, aumento de volumen de maxilares con predominio de maxilar inferior, asociado a adenopatías no dolorosas, palpables en región cervical. Ausencia de piezas dentarias $18,26,27$, y 37 . En tórax no se presentaban alteraciones musculares, y las costillas eran normales a la palpación. El resto del examen físico era normal. Al examen neurológico presentaba una visión de 20/ 30 en ambos ojos, asociada a diplopía que se acentuaba con la mirada extrema, fondo de ojo sin alteraciones, nervio óptico sano. El resto del examen neurológico era normal.

En la radiografía simple de cráneo se identificaron lesiones quísticas multiloculares definidas por bordes de hueso trabecular que comprometen el maxilar inferior, el maxilar superior, el hueso malar y elevan el piso de la órbita. En la radiografía panorámica, se evidenció la alineación anormal de las piezas erupcionadas y no erupcionadas, ausencia de piezas dentales y dientes flotantes (figura 2). En la Resonancia Nuclear Magnética de cara, se evidencio una importante expansión simétrica y quística de las paredes de la maxila y mandíbula con pérdida de continuidad de la pared cortical, constituyendo una imagen de panal de abejas. En el corte trasversal y coronal de la Resonancia, a la altura del piso de la orbita se evidencian lesiones quísticas que ejercen presión sobre las estructuras oculares (figura 3).

Mediante secuenciación del gen SH3BP2 (SH3-domain binding protein 2) se detecto una transversión $\mathrm{G}$ (Guanina) por $\mathrm{C}$ (Citosina) en el exón 9 del gen, que tiene como consecuencia una substitución de Glicina por Arginina (G420R) en la proteína del mismo nombre. Los demás miembros de la familia no mostraron mutaciones, considerándose que la mutación ocurrió fue un evento de novo. 


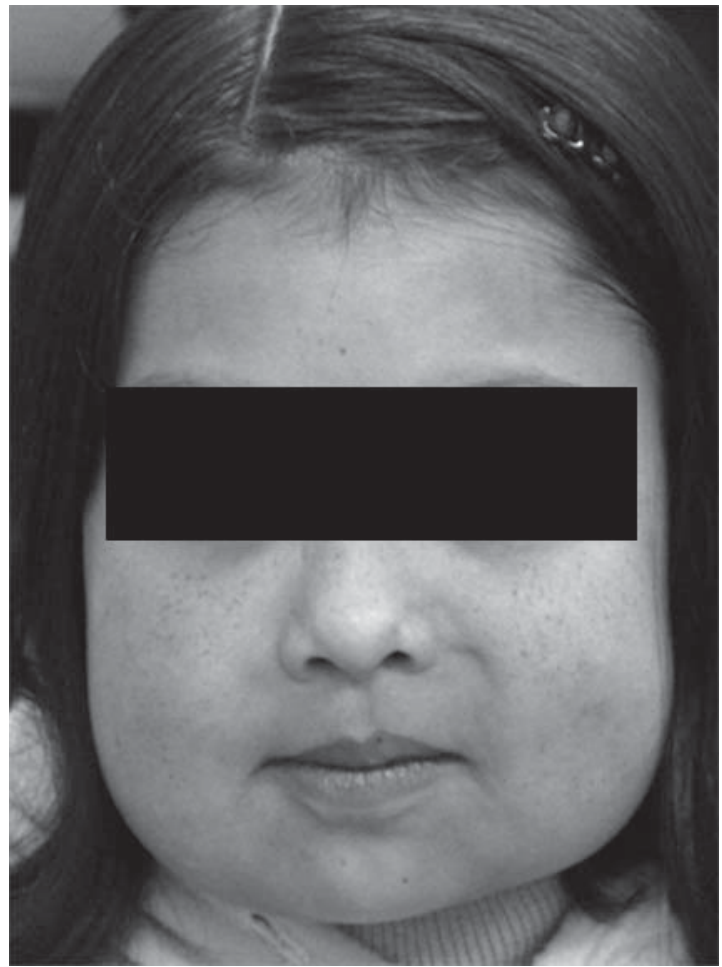

Figura 1. La apariencia y el incremento general del volumen facial de la paciente se deben a la presencia de lesiones quísticas multiloculares que comprometen los huesos de la cara.

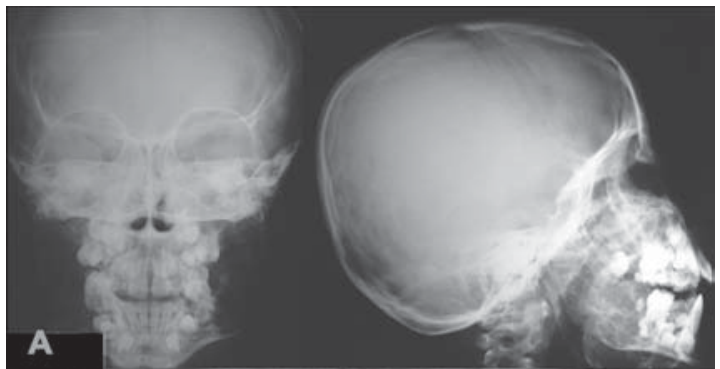

B

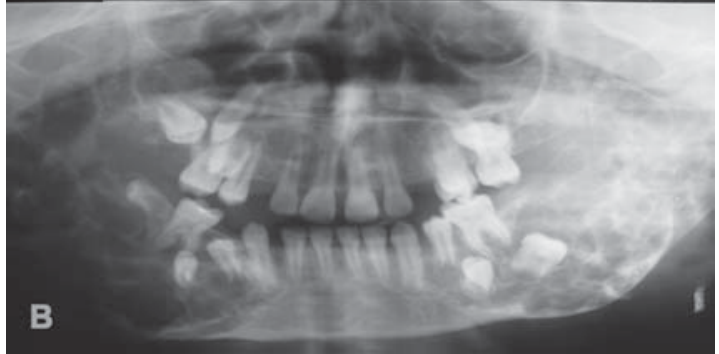

Figura 2. Radiografía panorámica se hace evidente la alineación anormal de las piezas erupcionadas y no erupcionadas, ausencia de piezas dentales y dientes flotantes.

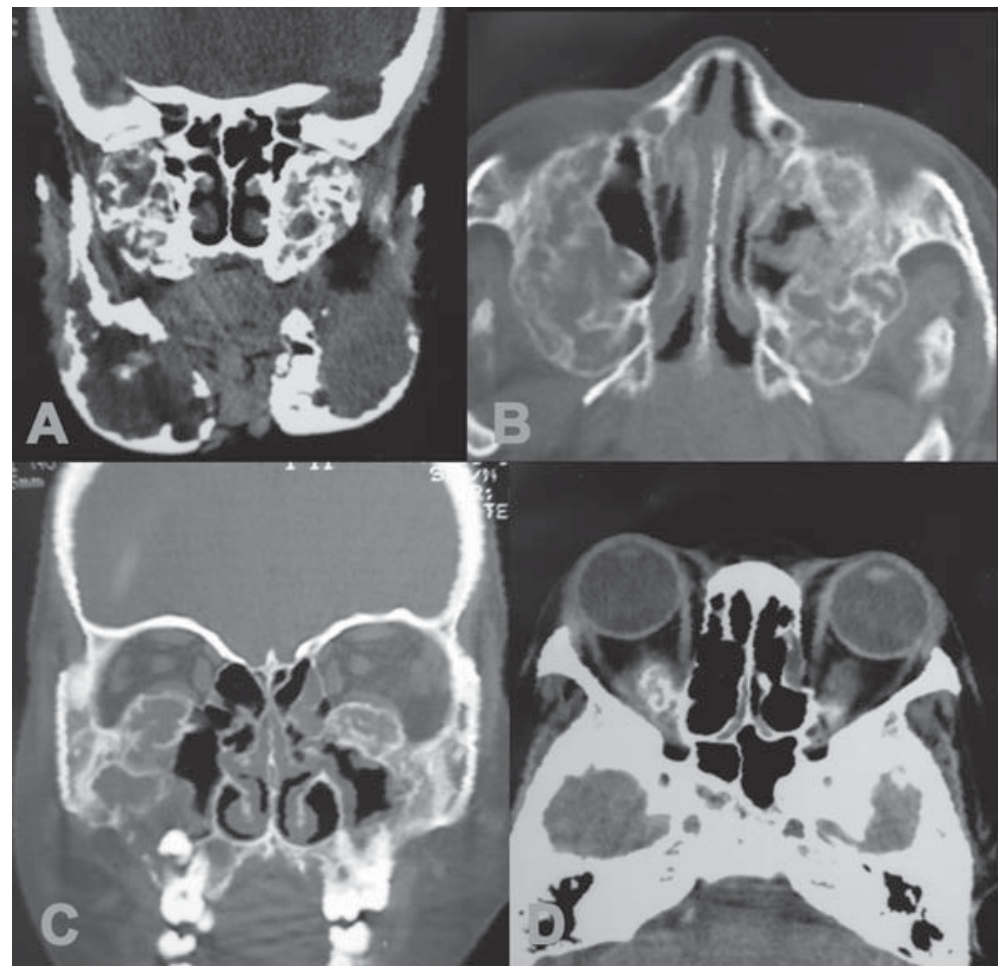

Figura 3. Las lesiones quísticas del piso de la orbita comprometen la estructuras oculares. 


\section{Discusión}

El Querubismo es una enfermedad autosómica dominante, con una penetrancia cercana al $100 \%$ en hombres, pero con una penetrancia reducida en mujeres que oscila en el 50 al $75 \%{ }^{7}$. La enfermedad se caracterizada por el aumento de tamaño no doloroso, de la mitad inferior de la cara, que inicia alrededor del tercer a cuarto año de la vida hasta la adolescencia $^{8}$. El volumen facial aumentado se acentúa debido al exagerado crecimiento de los ganglios sub-mandibulares. En la mayoría de los casos el crecimiento se detiene al final de la adolescencia, así el aspecto típico del Querubismo desaparece cuando las lesiones involucionan y alrededor de los 20 años las lesiones residuales no son reconocibles y la deformidad residual de los maxilares es infrecuente ${ }^{9}$.

Las radiografías revelan la presencia de cambios quísticos multiloculares en los huesos de la cara e infrecuentemente en la región anterior de las costillas ${ }^{10}$. De acuerdo a imágenes radiológicas y sintomatología similar el diagnóstico diferencial debe hacerse con la displasia fibrosa, granuloma de células gigantes, osteosarcoma, fibroma osificante juvenil, osteoma fibroso, quiste odontogénico e hiperparatirodismo ${ }^{11}$. La histopatología se caracteriza por la presencia de células osteoclásticas gigantes, diseminadas en tejido conectivo, con la presencia de células fusiformes y trabéculas osteoides bizarras $^{12}$.

A partir de las primeras descripciones clínicas se especuló que la enfermedad se originaba por la presión que ejercían los núcleos dentarios en crecimiento junto con una exagerada resorción de la decidua dental, es decir que desde la odontogénesis se definía el incremento del volumen óseo, esta teoría coincidía con la edad de aparición de la patología porque concordaba el aumento del volumen facial con el inicio de la mineralización del segundo molar (a la edad de 2 o 3 años) y explicaba la regresión espontánea durante la adolescencia cuando termina la odontogénesis molar ${ }^{13}$. Como consecuencia de esa teoría el Querubismo se clasificaba dentro del grupo de displasias fibrosas, pero se le denominaba: displasia fibrosa craneofacial hereditaria, por su componente mendeliano, pero con un patrón radiológico similar entre el Querubismo y la Displasia Fibrosa.

Sólo cuando Ueki y cols., identificaron que las mutaciones en el gen SH3BP2 causaban el Querubismo se sentaron las bases genéticas para clasificar la patología como una entidad separada. E1 Gen SH3BP2 esta localizado en 4 p16.3 y tiene 45,961 bases y 13 exones, transcribe una proteína de 561 aminoácidos y 63364 Daltons, esta proteína, se une de manera diferencial a dominios $\mathrm{SH} 3$ de ciertas proteínas de señal de traducción y se ha demostrado su expresión en las células multi-nucleadas y células estromales del tejido fibroso de las lesiones quísticas de los pacientes afectados ${ }^{14}$. Hyckel y cols, consideran que el Querubismo es un desorden inducido por señales alteradas en la transducción de la hormona paratiroidea. La anomalía se origina específicamente por la influencia de la proteína $\mathrm{SH} 3 \mathrm{BP} 2$ en la regulación de la unión del receptor para parato-hormona $(\mathrm{PTH})$ y la proteína relacionada con la parato-hormona (PTHrP) a través de la chaperona 14-3-3 que es un receptor del complejo $\mathrm{PTHrP} / \mathrm{PTH}$, este receptor es de fundamental importancia en la organización espacio-temporal de las células osteoclásticas, desarrollo del germen dental, dentición y modelamiento del hueso alveolar ${ }^{15}$.

Las principales complicaciones descritas de la enfermedad son la neuropatía óptica causada por el compromiso orbitario ${ }^{16}$, desordenes del sueño, lenguaje y masticación ${ }^{17}$ y obstrucción de la vía área ${ }^{18}$. En el caso presentado la paciente ya tiene compromiso de la vía visual, aunque sin signos de neuritis óptica, hasta el momento no ha presentado alteraciones respiratorias, en órganos de la fonación ni dificultad con la masticación, en algunos casos de Querubismo se ha recurrido a la descompresión quirúrgica de la orbita así como manejo quirúrgico reconstructivo de los maxilares ${ }^{19,20}$, sin embargo, en el caso de la paciente, se ha optado por una conducta expectante esperando que la involución de las lesiones al final de la adolescencia.

En los familiares de la probando, no se presentaron características clínicas de la enfermedad y se descarto una penetrancia reducida a través del estudio molecular en padres y her- 
manos, de tal modo que la asesoría se basa en una herencia dominante con una mutación de novo. Los antecedentes de la familia no son directamente relevantes con el caso del probando, pero llama la atención el antecedente constante de genu valgum el cual podría corresponder a un genu valgum familiar, pero esta posibilidad no se ha estudiado.

\section{Agradecimientos}

Agradecemos al Dr. Harmunt Peters del Institute of Medical Genetics, Charité Medical School, Humboldt University of Berlin, Alemania por llevar a cabo las pruebas moleculares. Agradecemos a la paciente y su familia por su colaboración para el desarrollo de este articulo.

\section{Referencias}

1.- Kozakiewicz M, Perczynska-Partyka W, Kobos J: Cherubism--clinical picture and treatment. Oral Dis 2001 7: 123-30.

2.- Lannon DA, Earley MJ: Cherubism and its charlatans. Br J Plast Surg. 2001; 54: 708-11.

3.- Ozkan Y, Varol A, Turker N, Aksakalli N, Basa S. Clinical and radiological evaluation of cherubism: a sporadic case report and review of the literature. Int $\mathrm{J}$ Pediatr Otorhinolaryngol 2003; 67 (9): 1005-12.

4.- Lewis R, Eversole J, Sapp P,Wysocki G: Contemporary oral and maxillofacial pathology. 2005; 4: 92-104.

5.- Jones WA, Gerrie J, Pritchard J. Cherubism--familial fibrous dysplasia of the jaws. J Bone Joint Surg $\mathrm{Br}$ 1950; 32-B: 334-47.

6.- Jones WA: Cherubism. A thumbnail sketch of its diagnosis and a conservative method of treatment. Oral Surg Oral Med Oral Pathol 1965; 20: 648-53.
7.- Peters WJ: Cherubism: a study of twenty cases from one family. ral Surg Oral Med Oral Pathol 1979; 47: 307-11.

8.- Pulse CL, Moses MS, Greenman D, Rosenberg SN, Zegarelli DJ: Cherubism: case reports and literature review. Dent Today 2001; 20: 100-3.

9.- Kaugars GE, Niamtu J 3rd, Svirsky JA: Cherubism: diagnosis, treatment, and comparison with central giant cell granulomas and giant cell tumors. Oral Surg Oral Med Oral Pathol 1992; 73: 369-74.

10.- Petkovska L, Ramadan S, Aslam MO: Cherubism: review of four affected members in a Kuwaiti family. Australas Radiol 2004; 48: 408-10.

11.- De Lange J, Van den Akker HP: Clinical and radiological features of central giant-cell lesions of the jaw. Oral Surg Oral Med Oral Pathol Oral Radiol Endod 2005; 99: 464-70.

12.- Stiller M, Urban $M$, Golder $W$, et al: Craniosynostosis in cherubism. Am J Med Genet 2000; 95: 325-31.

13.- Hyckel P, Berndt A, Schleier P, et al: Cherubism-new hypotheses on pathogenesis and therapeutic consequences. J Craniomaxillofac Surg 2005; 33: 618.

14.- Ueki Y, Tiziani V, Santanna $C$, et al: Mutations in the gene encoding c-Abl-binding protein SH3BP2 cause cherubism. Nature Genet 2001; 28: 125-6.

15.- Lietman SA, Yin L, Levine MA: SH3BP2 is an activator of NFAT activity and osteoclastogenesis. Biochem Biophys Res Commun 2008; 371: 644-8.

16.- Ahmadi AJ, Pirinjian GE, Sires BS: Optic neuropathy and macular chorioretinal folds caused by orbital cherubism. Arch Ophthalmol 2003; 121: 570-3.

17.- Ladhani S, Sundaram P, Joshi JM: Sleep disordered breathing in an adult with cherubism. Thorax 2003; 58: 552.

18.- Battaglia A, Merati A, Magit A: Cherubism and upper airway obstruction. Otolaryngol Head Neck Surg 2000; 122: $573-4$

19.- Carroll AL, Sullivan TJ: Orbital involvement in cherubism. Clin Experiment Ophthalmol 2001; 29: 38-40.

20.- Raposo-Amaral CE, de Campos Guidi M, Warren SM, et al: Two-stage surgical treatment of severe cherubism. Ann Plast Surg 2007; 58: 645-51. 